\title{
Association of working conditions including digital technology use and systemic inflammation among employees: study protocol for a systematic review
}

\author{
Helena C. Kaltenegger ${ }^{1 *}$ (D) Linda Becker ${ }^{2}$, Nicolas Rohleder ${ }^{2}$, Dennis Nowak ${ }^{1}$ and Matthias Weigl ${ }^{1}$
}

\begin{abstract}
Background: With the dynamic advancement of digitalization, working environments are changing and risk for employee stress may be increasing. Work stress has been associated with a dysregulation of inflammatory processes as a component of immune function. Systemic low-grade inflammation is discussed as a key player in the relation between stress exposure and chronic illness, such as cardiovascular diseases. The objective of this investigation will be to evaluate the association of working conditions including digital technology use and systemic inflammation among employees.
\end{abstract}

Methods: We designed and registered a study protocol for a systematic review of randomized controlled trials and prospective non-randomized studies (e.g., cohort, interrupted time series, or before-after studies). We will include studies conducted among adult workers reporting associations of working conditions and inflammatory activity. The outcome will be biomarkers of systemic low-grade inflammation on cell, plasma molecule and intracellular level, such as C-reactive protein, or different types of leukocytes, cytokines, etc. Literature searches will be conducted in several electronic databases (from January 1982 onwards), including PubMed/MEDLINE, Embase, PsycINFO, Web of Science, and CENTRAL. Two reviewers will independently screen all retrieved records, full-text articles, and extract data. The study methodological quality (or bias) will be appraised using appropriate tools. Our results will be described qualitatively. Random effects meta-analysis will be conducted, if feasible and appropriate. Additional analyses will be performed to explore potential sources of heterogeneity.

Discussion: This systematic review and meta-analysis will provide a synthesis of studies evaluating the association of working conditions and systemic inflammation. We anticipate our findings to identify knowledge gaps in the literature that future research should address. Moreover, results of our review may provide implications for corporate and public policy action for employee health promotion and prevention of occupational stress.

Systematic review registration: PROSPERO ID: CRD42020166887

Keywords: Work, Job, Health, Working conditions, Occupational stress, Digitalization, Technostress, Inflammation, Inflammatory markers, Immune system

\footnotetext{
* Correspondence: helena.kaltenegger@med.uni-muenchen.de

'Institute and Clinic for Occupational, Social and Environmental Medicine,

University Hospital, Ludwig-Maximilians-University of Munich, Ziemssenstraße

1, 80336 München, Germany

Full list of author information is available at the end of the article
}

(c) The Author(s). 2020 Open Access This article is licensed under a Creative Commons Attribution 4.0 International License, which permits use, sharing, adaptation, distribution and reproduction in any medium or format, as long as you give appropriate credit to the original author(s) and the source, provide a link to the Creative Commons licence, and indicate if changes were made. The images or other third party material in this article are included in the article's Creative Commons licence, unless indicated otherwise in a credit line to the material. If material is not included in the article's Creative Commons licence and your intended use is not permitted by statutory regulation or exceeds the permitted use, you will need to obtain permission directly from the copyright holder. To view a copy of this licence, visit http://creativecommons.org/licenses/by/4.0/ The Creative Commons Public Domain Dedication waiver (http://creativecommons.org/publicdomain/zero/1.0/) applies to the data made available in this article, unless otherwise stated in a credit line to the data. 


\section{Background}

In the light of contemporary and profound changes in the world of work coined by digitalization, the workplace may represent a significant cause of stress, and employee health promotion becomes increasingly important. Exposure to work stress has been associated with physical and mental ill health, such as cardiovascular diseases, type 2 diabetes, and clinical depression, as well as mortality [1-6]. With the dynamic advance of technologization and digitalization in humans' workplaces and private lives, stress experience related to the interaction with information (and communication) technologies and systems has become a phenomenon of rapidly growing scholarly interest. Research on technostress [7] and digital stress [8-11] has identified a broad range of potential sources of stress, such as techno-invasion, interruptions, information overload, complexity, invasion of privacy, etc. [12-15], and moreover, has revealed effects on the endocrine system with possible implications for immune function [16].

Sustained low-grade inflammation as a sub-component of the immune system is discussed as a central process in the association between stress exposure and severe longterm diseases [17-20]. Inflammation is mostly assessed by measuring levels of inflammatory markers in plasma or serum, including (proinflammatory) cytokines, such as interleukins (IL; mainly IL-1 $(\beta)$ and IL-6), tumor necrosis factors (TNF; mainly TNF- $\alpha$ ), interferons (IFN), and the acute-phase protein C-reactive protein (CRP) [21-23]. Several studies have shown associations between adverse working conditions, such as high effort-reward imbalance [24], organizational injustice or shift work, and inflammatory activity [25-27]. Reviews and meta-analyses indicate substantial evidence for the relation of acute and chronic psychosocial stress with immune function and inflammatory processes $[17,21,28,29]$. However, there is a paucity of reviews and meta-analyses examining systemic inflammatory processes due to working conditions and/or workrelated stress. Previous reviews and meta-analyses have focused on associations between workplace stress and immune function [30, 31], and on work-related psychosocial factors and inflammatory markers [32]. However, to our knowledge, there are no systematic reviews and metaanalyses investigating the strength of the evidence on the prospective association of various modern working conditions including digital technology use and employees' systemic inflammatory markers.

We plan to conduct a systematic review on the association of working conditions including digital technology use and systemic inflammation among employees. There are two aims within the planned review: The first aim will be to determine the current evidence on associations between working conditions and inflammation based on randomized controlled trials and prospective non- randomized studies and to assess if different classes of working conditions are differently associated with inflammatory markers. The second aim will be to identify if there are studies specifically investigating work-related use of digital technologies and inflammatory markers, and if so, evaluate their potential associations.

\section{Methods}

\section{Protocol registration and reporting information}

The present protocol has been registered within the PROSPERO database (registration ID: CRD42020166887). This protocol is being reported in accordance with the reporting guidance provided in the Preferred Reporting Items for Systematic Review and Meta-analysis Protocols (PRISMA-P) statement [33, 34] (see PRISMA-P checklist in Additional file 1). The proposed systematic review will be reported in accordance with the reporting guidance provided in the Preferred Reporting Items for Systematic Reviews and Meta-analyses (PRISMA) statement [35, 36]. Information on roles, responsibilities, and skills of review team members is provided in Additional file 2.

\section{Eligibility criteria}

Studies will be selected according to the following study characteristics: study design, participants, exposure/interventions, comparators, outcomes (PECO/ PICO framework):

- Study design: Eligible studies will be prospective field studies reporting associations between working conditions and systemic inflammation. We will include observational and interventional studies, i.e., randomized controlled trials and non-randomized studies of interventions, such as controlled beforeand-after studies or interrupted time series designs. There will be no restrictions by type of occupational setting. Laboratory studies will be excluded.

- Participants: We will include all types of adult workers and employee samples. We will consider all types of occupations, such as managers, professionals, technicians and associate professionals, clerical support workers, services and sales workers, agricultural workers, craft and related trades workers, plant and machine operators and assemblers, and elementary occupations (see [37]); as well as sectors, such as agriculture/forestry, chemical industries, commerce, construction, education, engineering, financial services, health services, transport, etc. (see [38]). Unemployed individuals, students, athletes, artists, military personnel, and clinical samples based on specific diagnoses will be excluded.

- Exposures/interventions: Studies assessing all kinds of working conditions will be eligible, encompassing a 
broad range of work- and employment-related aspects, like working time, compensation, mental and physical demands [39]. We will include studies examining all kinds of psychosocial factors at work, such as work environment, job content, and organizational conditions [40]. Moreover, studies focusing on work-related use of digital technologies and media as well as associated stressors, such as techno-overload or interruptions [15, 41], will be included. We define digital technologies as the entirety of all electronic devices (hardware) and applications (software) that use information based on number codes, and the entirety of all media coded in formats that can be processed by these devices and applications. Work-related digital technologies may comprise computers, e-mails, mobile phones, internet, messaging systems, artificial intelligence, autonomous systems, robots, virtual reality, etc. Studies examining specific environmental hazards, i.e., chemical or physical agents in the air, water, soil, food, or extreme heat, will be excluded. We will exclude studies assessing shiftwork (for a review, see, e.g., [42]) and socioeconomic status as exposure variables. Studies investigating all kinds of workplace-related interventions, that is, all measures directly or indirectly aiming at occupational health promotion (on or off site), will be eligible. We will exclude studies on nutraceutical interventions.

- Comparators: If applicable, the comparator group will be based on subjects not exposed to a specific working condition/exposed to a lesser extent or not exposed to a specific workplace intervention/ exposed to a different intervention.

- Outcomes: Our outcome of interest will be changes in markers of systemic low-grade inflammation measured in the blood or saliva. We will consider three main categories of indicators of systemic inflammation: cells, plasma molecules, and intracellular processes. Regarding cells, we will include studies examining leukocytes (and subtypes) and dendritic cells. With regard to plasma molecules, we will include studies on the acute-phase proteins CRP, fibrinogen, and serum amyloid $\mathrm{A}$, and on cytokines including different chemokines, interleukins, lymphokines, and monokines as well as IFN- $\gamma$ and TNF- $\alpha$. Cell-free DNA, inflammasomes, and intercellular adhesion molecule-1 will also be included as target outcomes. Concerning intracellular processes, we will include studies on the transcription factors AP-1, NF-IL6, and NF-kappa B, and on gene expression associated with inflammatory processes (see Table 1 for a list of included markers). We will exclude studies assessing inflammatory markers as indicators of organ damage, such as kidney injury. All inflammatory markers will be considered as main outcomes; there will be no prioritization or secondary outcomes. We will include studies with at least one follow-up measure, i.e., two consecutive measurements, of outcome variables.

We will include studies published from January 1982 (considering the introduction of the term technostress [7] in 1982) onwards. We will include articles in peerreviewed journals reported in the languages English and German. A list of possibly relevant titles in other languages will be provided in the final study report as an appendix. We will exclude conference proceedings, dissertations, or theses.

\section{Information sources and search strategy}

The primary source of relevant literature will be a structured search using several electronic databases (from 1982 onwards): PubMed/MEDLINE, Embase, PsycINFO, Web of Science, and Cochrane Central Register of Controlled Trials (CENTRAL). The secondary source of potentially relevant material will be a search for the difficult to locate literature, including Google Scholar. We will perform hand searching of reference lists of included studies and relevant reviews to identify additional eligible papers. Experts and prolific authors in the field will be contacted and consulted. The literature searches will be designed and conducted by the review team. The search will include a broad range of terms and keywords related to the PECO/PICO question (e.g., "worker", "job control", "social support", "communication technology", "digital stress", "inflammation", "immune system"). A full draft of the search strategy for PubMed/MEDLINE is provided in Additional file 3. This search strategy will be adapted to the other databases using the software Systematic Review Accelerator [43].

\section{Screening and selection procedure}

All retrieved titles and abstracts of identified articles will be imported into the software EndNote X8 (Thomson Reuters). The screening process will be conducted using the web and mobile application Rayyan [44]. Two independent reviewers (HK, MW) will conduct a systematic and stepwise selection of eligible studies, that is, screening of titles, abstracts, and full texts. Reviewers will discuss potential discrepancies until a consensus is reached. Potential conflicts between the two reviewers will be resolved after the consultation of a third reviewer (LB) from the study team. Excluded studies will be recorded. All steps of the study selection will be tested prior, in order to identify potential misunderstandings between the reviewers regarding the eligibility criteria or the software interface. This pre-test will include a random sample of 20 records. A flow diagram presenting the study selection process will be prepared [35]. 
Table 1 Outcome category, definition, and included inflammatory markers per category

\begin{tabular}{|c|c|c|}
\hline Outcome category & Definition of outcome category & Inflammatory markers (per outcome category) \\
\hline Cells & $\begin{array}{l}\text { Inflammation-related processes } \\
\text { on cell level as a component } \\
\text { of cellular immunity }\end{array}$ & $\begin{array}{l}\text { Leukocytes } \\
\text { Eosinophils } \\
\text { Granulocytes } \\
\text { Lymphocytes } \\
\text { Macrophages } \\
\text { Monocytes } \\
\text { Neutrophils } \\
\text { Dendritic cells }\end{array}$ \\
\hline \multirow[t]{5}{*}{ Plasma molecules } & \multirow[t]{5}{*}{$\begin{array}{l}\text { Inflammation-related processes } \\
\text { on plasma protein level as a } \\
\text { component of humoral immunity }\end{array}$} & $\begin{array}{l}\text { Acute-phase proteins } \\
\text { C-reactive protein (CRP) } \\
\text { Fibrinogen } \\
\text { Serum amyloid A }\end{array}$ \\
\hline & & $\begin{array}{l}\text { Cytokines } \\
\text { Chemokines } \\
\text { Interferon-gamma (IFN- }- \text { ) } \\
\text { Interleukins (IL) } \\
\text { Lymphokines } \\
\text { Monokines } \\
\text { Tumor necrosis factor-alpha (TNF-a) }\end{array}$ \\
\hline & & Cell-free DNA \\
\hline & & Inflammasomes \\
\hline & & Intercellular adhesion molecule-1 \\
\hline Intracellular processes & $\begin{array}{l}\text { Inflammation-related processes } \\
\text { on intracellular level }\end{array}$ & $\begin{array}{l}\text { Transcription factors } \\
\text { AP-1 } \\
\text { NF-IL6 } \\
\text { NF-kappa B } \\
\text { Gene expression } \\
\text { Transcripts for proteins associated with inflammatory processes } \\
\text { Transcriptomics focusing on or revealing inflammatory processes }\end{array}$ \\
\hline
\end{tabular}

\section{Data collection process}

Data will be extracted independently by two authors (HK, MW) and imported into Excel (Microsoft Office Professional Plus, 2016). This step will be pre-tested with five articles to test for feasibility and comprehensiveness. A third reviewer (NR) from the study team will be included as a consultant in case of disagreement. Several main categories and individual data will be extracted from all eligible articles (see Table 2). In the case of missing information, corresponding authors will be contacted to obtain information relevant to this review. If there are multiple reports of a single study, only the key paper will be included (authors will be contacted, if not clear).

\section{Data processing and classification of exposure and outcome variables}

With regard to the exposure variables, two reviewers (HK, MW) will perform a criteria-based classification of working conditions according to the scheme presented in Fig. 1. First, included studies will be categorized concerning their underlying theoretical model. Working conditions will be classified into job demands and resources as main categories with respective subcategories based on the following four models:
- Job demand-control model (JDC [45]): The JDC model postulates that mental strain in a workplace context results from the combination of the two dimensions job demands and job control. High job demands, such as time pressure or workload, and low decision latitude are associated with mental strain and job dissatisfaction.

- Job demand-control-support model (JDCS [46, 47]): This model is an extension of the JDC model by integrating the dimension social support.

- Job demands-resources model (JDR [48]): The JDR model suggests that high job demands lead to strain and health impairment, whereas high resources lead to increased motivation and productivity [49]. In the long-term, an interaction between extreme job demands, which lead to exhaustion and a lack of resources leading to disengagement from work, can result in the development of burnout [48].

- Challenge-hindrance stress model (C-H [50]). The C$\mathrm{H}$ stress model proposes that work stressors can be divided into two categories (challenge vs. hindrance stressors), which are differently associated (positively vs. negatively) with work outcomes (see [51, 52]). In the primary investigation, challenge stressors-related to the phenomenon of eustress-were shown to be positively associated with job satisfaction and 
Table 2 Main categories and data extracted from included articles

\begin{tabular}{|c|c|c|}
\hline \multicolumn{2}{|c|}{ Main categories } & \multirow{2}{*}{$\begin{array}{l}\text { Data to be extracted } \\
\text { - Authors and year of publication }\end{array}$} \\
\hline I & Study characteristics & \\
\hline & & - Study design \\
\hline & & - Country of study \\
\hline & & - Period of follow-up and follow-up rate \\
\hline & & - Occupational setting \\
\hline \multirow[t]{2}{*}{$\|$} & Samples & - Participants: demographics, professional characteristics, health-related variables \\
\hline & & - Sample size \\
\hline \multirow[t]{4}{*}{ III } & $\begin{array}{l}\text { Type and assessment of exposures/interventions } \\
\text { and comparators }\end{array}$ & $\begin{array}{l}\text { - Type of working condition (e.g., job demands, job control, workload, social support, } \\
\text { digital technology use) }\end{array}$ \\
\hline & & - Type of workplace intervention (e.g., physical activity, stress reduction) \\
\hline & & - Type of comparator \\
\hline & & - Methods of assessment \\
\hline \multirow[t]{3}{*}{ IV } & Type and assessment of outcomes & - Category and type of inflammatory markers \\
\hline & & - Source of outcomes (blood, saliva) \\
\hline & & - Method/technique of assessment \\
\hline \multirow[t]{5}{*}{ V } & Statistical analyses and reported results & - Type of statistical methods and analyses \\
\hline & & $\begin{array}{l}\text { - Means and variance metrics of inflammatory markers (e.g., standard deviation, } \\
\text { confidence intervals) }\end{array}$ \\
\hline & & $\begin{array}{l}\text { - Coefficients }(\beta, \gamma) \text { and/or measures of strength of associations between working } \\
\text { conditions and inflammatory markers (OR, RR, HR with SE, and/or } 95 \% \mathrm{Cl})\end{array}$ \\
\hline & & - Effect sizes (if reported or calculable) \\
\hline & & - $P$-values \\
\hline \multirow[t]{2}{*}{$\mathrm{VI}$} & Moderators/control of confounders & - Potential moderator or confounder variables or analyses (if reported) \\
\hline & & - Results of respective analyses (if reported) \\
\hline VII & Further study information & - Further information of potential interest (e.g., limitations, restrictions to validity) \\
\hline
\end{tabular}

negatively with job search, in contrast to distress evoking hindrance stressors found to be oppositely associated with these outcomes [50].

We are aware that hybrid models do exist in this context, such as the differentiated JDR model [53, 54], and we will classify studies accordingly, i.e., multiple allocations are possible. With regards to the category "resources", in line with the JDR model [48], we will focus on external resources since they are more likely to be subjected to job design approaches in contrast to rather stable internal resources, such as cognitive features (see [55]); we will further distinguish between control, taskrelated, organizational, and social resources. If working conditions in eligible publications are reported without an underlying model, these studies will be assigned to a residual category. In addition, we will conduct a featurebased classification of every study concerning specific characteristics of the work situation irrespective of the underlying model. First, we will identify if working conditions involve digital technology use or not (as defined above). Second, we will distinguish between mental vs. non-mental, i.e., intellectual vs. physical, working conditions. Third, we will consider the time frame of working conditions, i.e., we will differentiate between acute and chronic (provided by author definition) working conditions (see Fig. 1).

\section{Risk of bias in individual studies}

To evaluate the methodological quality of all eligible studies as well as potential limitations to validity, a standardized risk of bias assessment will be performed. Since this review will include investigations using different study designs, three different established tools to assess the risk of bias will be applied by two independent reviewers (HK, MW). (1) For randomized controlled trials, the Cochrane Risk of Bias Tool (RoB 2 [56]) will be used. (2) For non-randomized studies of interventions, the Risk Of Bias In Non-randomized Studies - of Interventions (ROBINS-I $[57,58]$ ) tool will be utilized. These two risk of bias assessment tools include sets of questions addressing different domains of potential sources of bias from selection to reporting, and to be answered with proposed judgements. (3) For prospective observational studies, the checklist Quality of Reporting of $\mathrm{Ob}$ servational Longitudinal Research [59] will be applied. In 


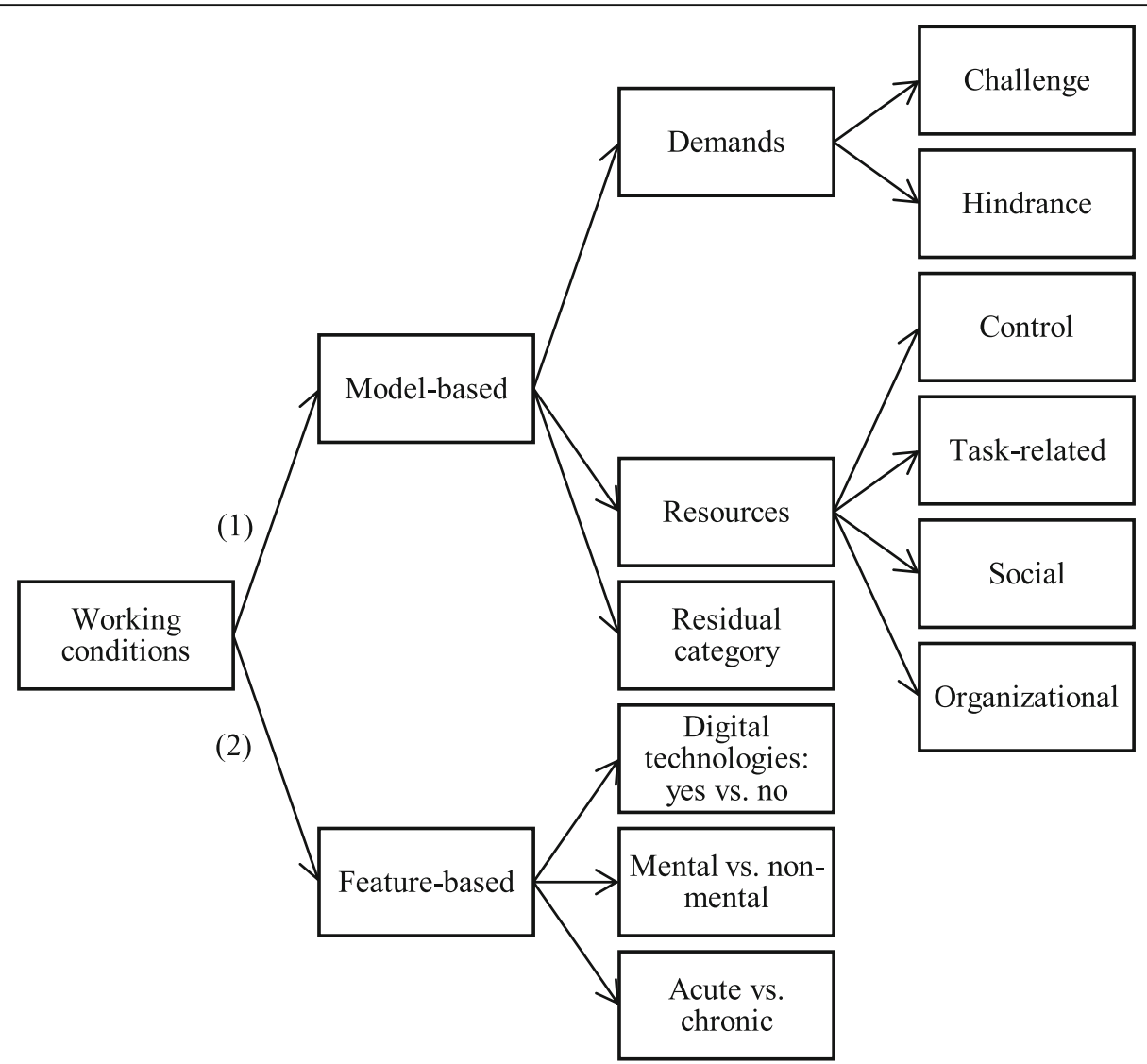

Fig. 1 Criteria-based algorithm for model-and feature-based classification of working conditions reported in eligible studies

case of disagreement between both reviewers, a third reviewer (LB) from the study team will be consulted and act as a tiebreaker to obtain a final evaluation. Our risk of bias assessment will be pre-tested using a sample of five, randomly selected articles of each study design category (see above). This step will ensure a joint understanding and application of the risk of bias evaluation tools between all reviewers.

\section{Data synthesis}

First, we will provide a qualitative summary of the information extracted from each included study and of our risk of bias assessment in narrative and tabular form. In case of substantial heterogeneity and inappropriateness of statistical pooling, we will apply graphical summary approaches for evidence synthesis in the absence of meta-analysis, i.e., harvest plots, effect directions, or bubble plots for summarizing information in an accessible and user-friendly manner (see [60]).

Secondly, if a sufficient number of high-quality studies with a relatively low level of heterogeneity is retrieved, we will quantitatively synthesize data from primary studies in a meta-analysis, using $R$ 3.5.2 (package: metafor [61]). Due to anticipated heterogeneity of effects in individual studies, we will select a random effects model based on the DerSimonian and Laird [62] method, in order to estimate the average of the effects across studies. Heterogeneity will be assessed by estimating the variance between primary studies using Cochran's $Q$ test [63] and $I^{2}$ statistic [64]. Results will be illustrated graphically using forest plots including individual study effects (step 1) and combined effect estimates (step 2) as well as confidence intervals, respectively [65].

\section{Additional analyses}

If the number of identified studies allows for, potential sources of heterogeneity will be explored further by subgroup analyses or meta-regression based on PECO/PICO and study design characteristics [66, 67]. We intend to perform subgroup analyses for potential effect modifications by age (e.g., young vs. middle-aged vs. elderly professionals) and sex (men vs. women), as age and sex are important determinants in work-related stress level, yet with inconsistent effects reported in the literature [68, 69]. Moreover, we plan to group studies regarding the type of exposure according to our criteria-based classification of working conditions (model based: demands vs. resources; feature based: digital vs. non-digital, mental 
vs. non-mental, acute vs. chronic). We will distinguish between observational and interventional study designs, and if enough studies will be identified, we intend to provide post hoc classifications regarding workplace interventions (e.g., organizational/structural vs. individual/ behavioral). In case a sufficient set of studies with a large variety of outcomes is retrieved, subgroup analyses based on our defined outcome categories (i.e., cells, plasma molecules, intracellular processes; see Table 1) will be undertaken. Finally, we plan to conduct sensitivity analyses to test for effects of exclusion of particular studies on the results based on methodological quality according to the risk of bias assessment and measurement/source of inflammatory markers (i.e., exclusion of studies using salivary markers) [67].

\section{Meta-biases}

The results of the review and meta-analysis will be critically examined with respect to sources of meta-bias, such as selective reporting within studies or publication bias across studies. We plan to generate a funnel plot, and tests for asymmetry (e.g., Egger's test [70]) including at least 10 studies (if possible) will be performed to check for small-study effects [67, 71, 72]. Furthermore, we will apply the critical appraisal tool for systematic reviews on randomized and/or non-randomized studies of healthcare interventions AMSTAR-2 [73].

\section{Confidence in cumulative evidence}

The strength of the body of evidence will be assessed by using the Grading of Recommendations Assessment, Development and Evaluation (GRADE), a system for rating quality of evidence and strength of recommendations $[74,75]$. Quality of evidence refers to the confidence that the estimates of the effect are correct and can be classified in one of four levels-high ("further research is very unlikely to change our confidence in the estimate of effect"), moderate ("further research is likely to have an important impact on our confidence in the estimate of effect and may change the estimate"), low ("further research is very likely to have an important impact on our confidence in the estimate of effect and is likely to change the estimate"), and very low ("any estimate of effect is very uncertain") [74, 76]. Threats to quality of evidence comprise study limitations, inconsistency of results, indirectness of evidence, imprecision as well as publication bias, and quality rating can be downgraded by the presence of these five factors [77]. The strength of recommendation is defined as the confidence that the desirable effects of an intervention outweigh its undesirable effects and can be graded as strong or weak [74, 78]. GRADE has been successfully used in the fields of clinical medicine, public health, and policy making, and more recently, its application has been advanced to studies in occupational and environmental health $[79,80]$.

\section{Discussion}

This protocol describes the methodology for a systematic review of the current study base on the association between working conditions including digital technology use and inflammatory markers in employees. We propose a rigorous assessment and synthesis of the current literature base with particular focus to high-quality studies, potentially allowing for evidence-based inferences concerning the actual state of knowledge on employees' inflammatory level that can be attributed to working conditions and job environment.

The protocol specifies all necessary steps of our systematic review limiting any potential bias that may occur a posteriori. It includes well-defined criteria for searching the scientific literature, study selection, risk of bias assessment, data extraction, and synthesis of findings. However, we are aware of potential sources of bias that may exist a priori and are foreseeable. Since our search does not include unpublished data and gray literature, we acknowledge that selection bias in terms of publication bias may occur. Moreover, language bias may be introduced by restrictions of eligible publications to English and German language. Although we cannot exclude that relevant studies have been conducted and/or published in other languages, we are confident that the validity and precision of our findings will not be substantially affected by language bias. Previous research suggests that restrictions beyond the English language introduce little to no systematic bias [81-83].

In the light of the limitations of previous and current research attempts [30-32], our investigation aims at advancing knowledge on the association of working conditions and systemic inflammation among employees particularly by three contributions: (1) We will only incorporate prospective studies to draw our effect estimates upon on a study base with high level of evidence designs. (2) A criteria-based classification of working conditions based on prominent job stress models will be provided, and digital technology use will be considered as a particular type of exposure. (3) Our review will include a comprehensive set of inflammatory markers, encompassing phenomena on different molecular biological levels (i.e., cells, plasma molecules, intracellular processes) and taking into account recent advancements in stress biomarker research, such as cell-free DNA. This broader scope expands the set of potential markers that indicate dysregulation of inflammatory processes associated with working conditions and will allow inferences concerning the feasibility and utility of bio-psychological markers for the assessment of employees' inflammation level in occupational contexts. 
Difficulties in the procedure of our planned review could relate to the retrieval of a large amount of records not relevant to our research question, due to the extensive set of search terms. An important challenge might be the rigorous and consistent exclusion of non-eligible studies according to our PECO/PICO characteristics. For instance, we anticipate that many of the retrieved studies include samples with previous medical conditions, such as cardiovascular diseases, or address inflammation as an acute clinical condition (e.g., in connection with injury) rather than chronic subclinical inflammation. Any amendments made to the protocol will be depicted and documented in the final publication of the review. The completed review is intended to be published in a peerreviewed journal in the field of occupational medicine or work psychology and will be presented at scientific conferences and other scientific outlets.

Several limitations of our anticipated investigation have to be considered on individual study and review level. Although our classification of working conditions is based on well-established occupational stress models, the selection may be regarded as arbitrary since other theories and models of great importance do exist in this field (e.g., effort-reward imbalance model [24]). Moreover, the validity and key propositions of the included models remain subject to scientific scrutiny: While considerable support for additive effects of job demands, job control and social support on psychological well-being ("strain hypothesis", "iso-strain hypothesis") has been found, evidence on moderating effects of job control or social support ("buffer hypothesis") is less consistent, and support in longitudinal compared with crosssectional studies appears to be weaker [84, 85]. Concerning the $\mathrm{C}-\mathrm{H}$ model, negative associations with key variables, such as psychological strains or physical health, have been demonstrated for both types of stressors in a recent meta-analysis, confining applicability of the model to few outcomes and questioning the alleged beneficial role of challenge stressors [86]. Nevertheless, keeping these limitations in mind, we assume that our suggested algorithm provides a sensible and feasible categorization of all sorts of studied working conditions. With regard to digital working conditions, we acknowledge that possible applications of digital technologies are multimodal and workplace settings significantly differ in their utilization of tools and modes of digital communication and information technologies, what may limit comparisons across professional settings and samples [87]. Furthermore, we anticipate potential limitations concerning the validity of the outcome inflammation. The selection of inflammatory markers often depends on aspects of measurability and feasibility rather than their pure indicative value for inflammation. Hence, we expect to detect a large body of research on CRP measurements, but, at the same time, we aim to capture other useful parameters of chronic low-grade inflammation by including a broad range of markers previously identified in stress research in our search strategy. With respect to the assessment method of inflammatory markers, we are aware of potential confinements regarding salivary markers (see $[17,88])$ and we will consider the assessment method in the data analysis (see above). In addition, inflammation involves a complex interplay of biological processes and should not be assessed in isolation underlining the necessity of adjusting for other variables, such as general health, including physical and mental health conditions associated with inflammation as well as anthropometric parameters, most importantly body fat percentage (or BMI, WHR, etc.). Lastly, the generalizability of the findings of our review will be limited to the working population.

Given the increasing interest and need for knowledge on the effects of modern working conditions on employee health and well-being, we regard our research question as highly relevant. Although we are aware of the difficulties concerning the feasibility of studies with rigor designs and high-level methodology in occupational settings (i.e., randomized controlled trials), we assume that our review results will inform future research in this field in several ways. First, our findings will reveal recommendations for the conductance of high-level investigations in occupational practice settings. Second, the findings will provide guidance for future studies on approaches to improve working conditions with the objective to promote employee health and well-being. Third, this review may help to identify research gaps concerning the effects of specific, but important working conditions, such as those shaped by recent societal developments. Eventually, as a practical implication, collated evidence on the effects of workplace interventions on systemic inflammation may yield indications for corporate and public policy action on employee health promotion.

\section{Supplementary information}

Supplementary information accompanies this paper at https://doi.org/10. 1186/s13643-020-01463-x.

Additional file 1. PRISMA-P checklist (file format: pdf)

Additional file 2. Review team roles and responsibilities (file format: pdf)

Additional file 3. Search strategy for PubMed/MEDLINE (file format: pdf)

\section{Abbreviations}

IL: Interleukin; TNF: Tumor necrosis factor; IFN: Interferon; CRP: C-reactive protein; AP-1: Activator protein 1; NF-IL6: Nuclear factor for interleukin-6 expression; NF-kappa B: Nuclear factor "kappa-light-chain-enhancer" of activated B cells; JDC: Job demand-control model; JDCS: Job demandcontrol-support model; JDR: Job demands-resources model; C-H: Challengehindrance stress model; BMI: Body mass index; WHR: Waist-to-hip ratio

\section{Acknowledgements}

We thank the Bavarian research association ForDigitHealth, in particular the agency and all members for their support and knowledge contributing to 
this work. Moreover, we would like to thank Daloha Rodríguez-Molina for her great advice on technical tools facilitating the performance of this systematic review.

\section{Role of funder}

The Bavarian Ministry of Science and Arts is funding this review (and metaanalysis) project. The funder is not involved in the protocol development, review conduct, data analyses, interpretation, and dissemination of the results. The views expressed are those of the authors and not necessarily those of the funders.

\section{Authors' contributions}

$H K, M W, L B, N R$, and DN contributed to the conception and design of the review; HK developed the search strategy and wrote the first draft of the manuscript; MW, LB, and NR wrote sections of the protocol. All authors contributed to manuscript revision, read and approved the submitted version. MW is the guarantor of the review.

\section{Funding}

This work is part of the Bavarian Research Association on Healthy Use of Digital Technologies and Media (ForDigitHealth), funded by the Bavarian Ministry of Science and Arts. MW's research is supported by the Munich Centre for Health Sciences (MC-Health). Open access funding provided by Projekt DEAL.

\section{Availability of data and materials}

Not applicable.

\section{Ethics approval and consent to participate}

Not applicable.

\section{Consent for publication}

Not applicable.

\section{Competing interests}

The authors declare that they have no competing interests.

\section{Author details}

${ }^{1}$ Institute and Clinic for Occupational, Social and Environmental Medicine, University Hospital, Ludwig-Maximilians-University of Munich, Ziemssenstraße 1, 80336 München, Germany. ${ }^{2}$ Chair of Health Psychology, Institute of Psychology, Friedrich-Alexander University Erlangen-Nürnberg, Erlangen, Germany.

Received: 12 March 2020 Accepted: 21 August 2020

Published online: 28 September 2020

\section{References}

1. Kivimäki $M$, Kawachi I. Work stress as a risk factor for cardiovascular disease. Curr Cardiol Rep 2015; 17(9): 630 [https://doi.org/10.1007/s11886-015-06308][PMID: 26238744].

2. Kivimäki $M$, Nyberg $S T$, Batty $G D$, et al. Job strain as a risk factor for coronary heart disease: a collaborative meta-analysis of individual participant data. Lancet. 2012;380(9852):1491-7. https://doi.org/10.1016/S01406736(12)60994-5.

3. Madsen IEH, Nyberg ST, Magnusson Hanson LL, et al. Job strain as a risk factor for clinical depression: systematic review and meta-analysis with additional individual participant data. Psychol Med 2017; 47(8): 1342-56 [https://doi.org/10.1017/S003329171600355X][PMID: 28122650].

4. Taouk Y, Spittal MJ, LaMontagne AD, Milner AJ. Psychosocial work stressors and risk of all-cause and coronary heart disease mortality: a systematic review and meta-analysis. Scand J Work Environ Health 2020; 46(1): 19-31 [https://doi.org/10.5271/sjweh.3854][PMID: 31608963]

5. Fishta A, Backé E-M. Psychosocial stress at work and cardiovascular diseases: an overview of systematic reviews. Int Arch Occup Environ Health 2015; 88(8): 997-1014 [https://doi.org/10.1007/s00420-015-1019-0][PMID: 25687981].

6. Fransson El, Nyberg ST, Heikkilä K, et al. Job strain and the risk of stroke: an individual-participant data meta-analysis. Stroke 2015; 46(2): 557-9 [https:// doi.org/10.1161/STROKEAHA.114.008019][PMID: 25563644].
7. Brod C. Managing technostress: optimizing the use of computer technology. The Personnel Journal 1982; (61(10)): 753-7.

8. Reinecke L, Aufenanger S, Beutel ME, et al. Digital stress over the life span: the effects of communication load and Internet multitasking on perceived stress and psychological health impairments in a German probability sample. Media Psychol. 2017;20(1):90-115. https://doi.org/10.1080/15213269. 2015.1121832

9. Weinstein EC, Selman RL. Digital stress: adolescents' personal accounts. New Media Soc. 2016;18(3):391-409. https://doi.org/10.1177/1461444814543989.

10. Weinstein EC, Selman RL, Thomas S, Kim J-E, White AE, Dinakar K. How to cope with digital stress. J Adolesc Res. 2016;31(4):415-41. https://doi.org/10. $1177 / 0743558415587326$.

11. Hefner D, Vorderer P. Digital stress. Permanent connectedness and multitasking. In: Reinecke L, Oliver MB, editors. The Routledge handbook of media use and well-being: international perspective on theory and research on positive media effects. New York, NY: Routledge 2017; 237-49.

12. Tarafdar M, Cooper CL, Stich J-F. The technostress trifecta - techno eustress, techno distress and design: theoretical directions and an agenda for research. Inf Syst J. 2019:29(1):6-42. https://doi.org/10.1111/isj.12169.

13. Pirkkalainen $H$, Salo M. Two decades of the dark side in the information systems basket: suggesting five areas for future research; 2016.

14. Ragu-Nathan TS, Tarafdar M, Ragu-Nathan BS, Tu Q. The consequences of technostress for end users in organizations: conceptual development and empirical validation. Inf Syst Res. 2008;19(4):417-33. https://doi.org/10.1287/ isre.1070.0165

15. Ayyagari R, Grover V, Purvis R. Technostress: technological antecedents and implications. MIS Quarterly. 2011;35(4):831-58.

16. Riedl R. On the biology of technostress. SIGMIS Database. 2012;44(1):18. https://doi.org/10.1145/2436239.2436242.

17. Rohleder N. Stress and inflammation - the need to address the gap in the transition between acute and chronic stress effects. Psychoneuroendocrinology 2019; 105: 164-71.[https://doi.org/10.1016/j. psyneuen.2019.02.021][PMID: 30826163]

18. Couzin-Frankel J. Inflammation bares a dark side. Science 2010; 330(6011): 1621.[https://doi.org/10.1126/science.330.6011.1621][PMID: 21163993].

19. Liu $Y-Z$, Wang $Y-X$, Jiang C-L. Inflammation: the common pathway of stressrelated diseases. Front Hum Neurosci 2017; 11: 316 [https://doi.org/10.3389/ fnhum.2017.00316][PMID: 28676747].

20. Katsiari CG, Bogdanos DP, Sakkas LI. Inflammation and cardiovascular disease. WJTM. 2019:8(1):1-8. https://doi.org/10.5528/wjtm.v8.i1.1.

21. Segerstrom SC, Miller GE. Psychological stress and the human immune system: a meta-analytic study of 30 years of inquiry. Psychol Bull 2004; 130(4): 601-30 [https://doi.org/10.1037/0033-2909.130.4.601][PMID: 15250815].

22. Hänsel A, Hong S, Cámara RJA, Känel R von. Inflammation as a psychophysiological biomarker in chronic psychosocial stress. Neurosci Biobehav Rev 2010; 35(1): 115-21 [https://doi.org/10.1016/j.neubiorev.2009. 12.012][PMID: 20026349].

23. Wirtz PH, Känel R von. Psychological stress, inflammation, and coronary heart disease. Curr Cardiol Rep 2017; 19(11): 111 [https://doi.org/10.1007/ s11886-017-0919-x][PMID: 28932967].

24. Siegrist J. Adverse health effects of high-effort/low-reward conditions. J Occup Health Psychol. 1996;1(1):27-41. https://doi.org/10.1037//1076-8998.1.1.27.

25. Bellingrath S, Rohleder N, Kudielka BM. Healthy working school teachers with high effort-reward-imbalance and overcommitment show increased pro-inflammatory immune activity and a dampened innate immune defence. Brain Behav Immun 2010; 24(8): 1332-9 [https://doi.org/10.1016/j. bbi.2010.06.011][PMID: 20599495].

26. Elovainio M, Ferrie JE, Singh-Manoux A, et al. Organisational justice and markers of inflammation: the Whitehall II study. Occup Environ Med 2010; 67(2): 78-83 [https://doi.org/10.1136/oem.2008.044917][PMID: 19773285].

27. Kwak HS, Park HO, Kim YO, et al. The effect of shift work on high sensitivity C-reactive protein level among female workers. Ann Occup Environ Med 2019; 31: e5 [https://doi.org/10.35371/aoem.2019.31. e5][PMID: 31543966].

28. Marsland AL, Walsh C, Lockwood K, John-Henderson NA. The effects of acute psychological stress on circulating and stimulated inflammatory markers: a systematic review and meta-analysis. Brain Behav Immun 2017; 64: 208-19 [https://doi.org/10.1016/j.bbi.2017.01.011][PMID: 28089638].

29. Herbert TB, Cohen S. Stress and immunity in humans: a meta-analytic review. Psychosom Med 1993; 55(4): 364-79 [https://doi.org/10.1097/ 00006842-199307000-00004][PMID: 8416086]. 
30. Nakata A. Psychosocial job stress and immunity: a systematic review. Methods Mol Biol 2012; 934: 39-75 [https://doi.org/10.1007/978-1-62703071-7_3][PMID: 22933140].

31. Eddy P, Heckenberg R, Wertheim EH, Kent S, Wright BJ. A systematic review and meta-analysis of the effort-reward imbalance model of workplace stress with indicators of immune function. J Psychosom Res 2016; 91: 1-8 [https:// doi.org/10.1016/j.jpsychores.2016.10.003][PMID: 27894456].

32. Eguchi H, Watanabe K, Kawakami N, et al. Psychosocial factors at work and inflammatory markers: protocol for a systematic review and meta-analysis. BMJ Open 2018; 8(8): e022612 [https://doi.org/10.1136/bmjopen-2018022612][PMID: 30158233].

33. Moher D, Shamseer $L$, Clarke $M$, et al. Preferred reporting items for systematic review and meta-analysis protocols (PRISMA-P) 2015 statement. Syst Rev 2015; 4: 1 [https://doi.org/10.1186/2046-4053-4-1][PMID: 25554246].

34. Shamseer $L$, Moher $D$, Clarke $M$, et al. Preferred reporting items for systematic review and meta-analysis protocols (PRISMA-P) 2015: elaboration and explanation. BMJ 2015; 350: g7647 [https://doi.org/10.1136/bmj. g7647][PMID: 25555855]

35. Moher D, Liberati A, Tetzlaff J, Altman DG. Preferred reporting items for systematic reviews and meta-analyses: the PRISMA statement. BMJ 2009; 339: b2535 [https://doi.org/10.1136/bmj.b2535][PMID: 19622551].

36. Liberati A, Altman DG, Tetzlaff J, et al. The PRISMA statement for reporting systematic reviews and meta-analyses of studies that evaluate healthcare interventions: explanation and elaboration. BMJ 2009; 339: b2700 [https:// doi.org/10.1136/bmj.b2700][PMID: 19622552].

37. International Labour Organization (ILO). International Standard Classification of Occupations (ISCO-08): structure, group definitions and correspondence tables. Geneva: International Labour Office 2012

38. International Labour Organization (ILO). Industries and sectors; 1996-2020. Available from: URL: https://www.ilo.org/global/industries-and-sectors/ lang\%2D\%2Den/index.htm.

39. International Labour Organization (ILO). Working conditions; 1996-2020. Available from: URL: https://www.ilo.org/global/topics/working-conditions/ lang\%2D\%2Den/index.htm.

40. International Labour Office, Joint ILO/WHO Committee on Occupational Health. Psychosocial factors at work: recognition and control: report of the Joint ILO/WHO Committee on Occupational Health, Ninth Session, Geneva, 18-24 September 1984. Geneva: International Labour Office 1986.

41. Tarafdar M, Tu Q, Ragu-Nathan BS, Ragu-Nathan TS. The impact of technostress on role stress and productivity. J Manag Inf Syst. 2007;24(1): 301-28. https://doi.org/10.2753/MIS0742-1222240109.

42. Puttonen S, Härmä M, Hublin C. Shift work and cardiovascular disease pathways from circadian stress to morbidity. Scand J Work Environ Health 2010; 36(2): 96-108. [https://doi.org/10.5271/sjweh.2894][PMID: 20087536].

43. Systematic Review (SR-) Accelerator. Institute for Evidence-Based Healthcare, Bond University. Available from: URL: http://sr-accelerator.com/\#/.

44. Ouzzani M, Hammady H, Fedorowicz Z, Elmagarmid A. Rayyan-a web and mobile app for systematic reviews. Syst Rev 2016; 5(1): 210 [https://doi.org/ 10.1186/s13643-016-0384-4][PMID: 27919275].

45. Karasek RA. Job demands, job decision latitude, and mental strain: implications for job redesign. Adm Sci Q. 1979;24(2):285. https://doi.org/10. 2307/2392498

46. Johnson JV, Hall EM, Theorell T. Combined effects of job strain and social isolation on cardiovascular disease morbidity and mortality in a random sample of the Swedish male working population. Scand J Work Environ Health 1989; 15(4): 271-9 [https://doi.org/10.5271/sjweh.1852][PMID: 2772582].

47. Johnson JV, Hall EM. Job strain, work place social support, and cardiovascular disease: a cross-sectional study of a random sample of the Swedish working population. Am J Public Health 1988; 78(10): 1336-42 [https://doi.org/10.2105/ajph.78.10.1336][PMID: 3421392].

48. Demerouti E, Bakker AB, Nachreiner F, Schaufeli WB. The job demandsresources model of burnout. J Appl Psychol. 2001;86(3):499-512. https://doi. org/10.1037/0021-9010.86.3.499.

49. Schaufeli WB, Taris TW. A critical review of the job demands-resources model: implications for improving work and health. In: Bauer GF, Hämmig $\mathrm{O}$, editors. Bridging occupational, organizational and public health. Dordrecht: Springer Netherlands 2014; 43-68.

50. Cavanaugh MA, Boswell WR, Roehling MV, Boudreau JW. An empirical examination of self-reported work stress among U.S. managers. Journal of Applied Psychology 2000; 85(1): 65-74 [https://doi.org/10.1037//0021-9010. 85.1.65][PMID: 10740957].
51. Lepine JA, Podsakoff NP, Lepine MA. A meta-analytic test of the challenge stressor-hindrance stressor framework: an explanation for inconsistent relationships among stressors and performance. AMJ. 2005;48(5):764-75. https://doi.org/10.5465/amj.2005.18803921.

52. Podsakoff NP, Lepine JA, Lepine MA. Differential challenge stressorhindrance stressor relationships with job attitudes, turnover intentions, turnover, and withdrawal behavior: a meta-analysis. Journal of Applied Psychology 2007; 92(2): 438-54 [https://doi.org/10.1037/0021-9010.92.2. 438][PMID: 17371090].

53. van den Broeck $A$, de Cuyper $N$, de Witte $H$, Vansteenkiste M. Not all job demands are equal: differentiating job hindrances and job challenges in the job demands-resources model. European Journal of Work and Organizational Psychology. 2010;19(6):735-59. https://doi.org/10.1080/ 13594320903223839

54. Schneider A, Hornung S, Weigl M, Glaser J, Angerer P. Does it matter in the long run? Longitudinal effects and interactions in the differentiated job demands-resources model. European Journal of Work and Organizational Psychology. 2017;26(5):741-54. https://doi.org/10.1080/1359432X.2017. 1347561.

55. Richter P, Hacker W. Belastung und Beanspruchung: Stress, Ermüdung und Burnout im Arbeitsleben. 5. Auflage. Kröning: Asanger Verlag 2017.

56. Sterne JAC, Savović J, Page MJ, et al. RoB 2: a revised tool for assessing risk of bias in randomised trials. BMJ 2019; 366: 14898 [https://doi.org/10.1136/ bmj.|4898][PMID: 31462531].

57. Sterne JA, Hernán MA, Reeves BC, et al. ROBINS-l: a tool for assessing risk of bias in non-randomised studies of interventions. BMJ 2016; 355: i4919 [https://doi.org/10.1136/bmj.i4919][PMID: 27733354]

58. McAleenan, A., Shepperd, S., Waddington, H., Higgins, J. on behalf of the development group for ROBINS-I, editor. Extending ROBINS-I for the assessment of interrupted time series and controlled before-after studies. Abstracts of the Global Evidence Summit. (9 Suppl 1). Cape Town, South Africa; 2017.

59. Tooth L, Ware R, Bain C, Purdie DM, Dobson A. Quality of reporting of observational longitudinal research. Am J Epidemiol 2005; 161(3): 280-8 [https://doi.org/10.1093/aje/kwi042][PMID: 15671260].

60. Burns J, Polus S, Brereton L, et al. Looking beyond the forest: using harvest plots, gap analysis, and expert consultations to assess effectiveness, engage stakeholders, and inform policy. Res Synth Methods 2018; 9(1): 132-40 [https://doi.org/10.1002/jrsm.1284][PMID: 29106058].

61. Viechtbauer W. Conducting meta-analyses in $\mathrm{R}$ with the metafor Package. J. Stat. Soft. 2010; 36(3) [https://doi.org/10.18637/jss.v036.i03].

62. DerSimonian R, Laird N. Meta-analysis in clinical trials. Control Clin Trials. 1986:7(3):177-88. https://doi.org/10.1016/0197-2456(86)90046-2.

63. Cochran WG. The combination of estimates from different experiments. Biometrics. 1954;10(1):101. https://doi.org/10.2307/3001666.

64. Higgins JPT, Thompson SG, Deeks JJ, Altman DG. Measuring inconsistency in meta-analyses. BMJ 2003; 327(7414): 557-60 [https://doi.org/10.1136/bmj. 327.7414.557][PMID: 12958120]

65. McKenzie, J.E., Brennan, S.E., Ryan, R.E., Thomson, H.J., Johnston, R.V. Chapter 9: Summarizing study characteristics and preparing for synthesis. In: Higgins JPT, Thomas J, Chandler J, et al., editors. Cochrane handbook for systematic reviews of interventions. version 6.0 (updated July 2019). Cochrane 2019.

66. Deeks, J.J., Higgins, J.P.T., Altman, D.G. Analysing data and undertaking meta-analyses. In: Higgins JPT, Thomas J, Chandler J, et al., editors. Cochrane handbook for systematic reviews of interventions. version 6.0 (updated July 2019). Cochrane 2019

67. Page MJ, Altman DG, McKenzie JE, et al. Flaws in the application and interpretation of statistical analyses in systematic reviews of therapeutic interventions were common: a cross-sectional analysis. Journal of Clinical Epidemiology 2018; 95: 7-18 [https://doi.org/10.1016/j.jclinepi.2017.11. 022][PMID: 29203419].

68. Gyllensten K, Palmer S. The role of gender in workplace stress: a critical literature review. Health Educ J. 2005;64(3):271-88. https://doi.org/10.1177/ 001789690506400307

69. Rauschenbach C, Krumm S, Thielgen M, Hertel G. Age and work-related stress: a review and meta-analysis. Journal of Managerial Psych. 2013;28(7/8): 781-804. https://doi.org/10.1108/JMP-07-2013-0251.

70. Egger M, Davey Smith G, Schneider M, Minder C. Bias in meta-analysis detected by a simple, graphical test. BMJ 1997; 315(7109): 629-34 [https://doi.org/10.1136/bmj.315.7109.629][PMID: 9310563]. 
71. Sterne JAC, Sutton AJ, loannidis JPA, et al. Recommendations for examining and interpreting funnel plot asymmetry in meta-analyses of randomised controlled trials. BMJ 2011; 343: d4002 [https://doi.org/10.1136/bmj. d4002][PMID: 21784880].

72. Sterne JAC, Gavaghan D, Egger M. Publication and related bias in metaanalysis. J Clin Epidemiol. 2000;53(11):1119-29. https://doi.org/10.1016/ s0895-4356(00)00242-0.

73. Shea BJ, Reeves BC, Wells G, et al. AMSTAR 2: a critical appraisal tool for systematic reviews that include randomised or non-randomised studies of healthcare interventions, or both. BMJ 2017; 358 : j4008 [https://doi.org/10. 1136/bmj.j4008][PMID: 28935701].

74. Guyatt GH, Oxman AD, Vist GE, et al. GRADE: an emerging consensus on rating quality of evidence and strength of recommendations. BMJ 2008; 336(7650): 924-6 [https://doi.org/10.1136/bmj.39489.470347.AD][PMID: 18436948].

75. Atkins $D$, Best $D$, Briss PA, et al. Grading quality of evidence and strength of recommendations. BMJ 2004; 328(7454): 1490 [https://doi.org/10.1136/bmj. 328.7454.1490][PMID: 15205295].

76. Balshem $H$, Helfand $M$, Schünemann $H$ J, et al. GRADE guidelines: 3. Rating the quality of evidence. Journal of Clinical Epidemiology 2011; 64(4): 401-6 [https://doi.org/10.1016/j.jclinepi.2010.07.015.][PMID: 21208779].

77. Guyatt GH, Oxman AD, Kunz R, Vist GE, Falck-Ytter Y, Schünemann HJ. What is "quality of evidence" and why is it important to clinicians? BMJ 2008; 336(7651): 995-8 [https://doi.org/10.1136/bmj.39490.551019.BE][PMID: 18456631].

78. Andrews J, Guyatt G, Oxman AD, et al. GRADE guidelines: 14. Going from evidence to recommendations: the significance and presentation of recommendations. Journal of Clinical Epidemiology 2013; 66(7): 719-25 [https://doi.org/10.1016/j.jclinepi.2012.03.013][PMID: 23312392].

79. Morgan RL, Thayer KA, Bero L, et al. GRADE: assessing the quality of evidence in environmental and occupational health. Environ Int 2016; 92-93: 611-6 [https://doi.org/10.1016/j.envint.2016.01.004][PMID: 26827182].

80. Morgan RL, Beverly B, Ghersi D, et al. GRADE guidelines for environmental and occupational health: a new series of articles in Environment International. Environ Int 2019; 128: 11-2 [https://doi.org/10.1016/j.envint. 2019.04.016][PMID: 31029974].

81. Morrison A, Polisena J, Husereau D, et al. The effect of English-language restriction on systematic review-based meta-analyses: a systematic review of empirical studies. Int J Technol Assess Health Care 2012; 28(2): 138-44 [https://doi.org/10.1017/S0266462312000086][PMID: 22559755].

82. Jüni $P$, Holenstein F, Sterne J, Bartlett C, Egger M. Direction and impact of language bias in meta-analyses of controlled trials: empirical study. Int J Epidemiol 2002; 31(1): 115-23 [https://doi.org/10.1093/ije/31.1.115][PMID: 11914306].

83. Moher D, Pham B, Lawson ML, Klassen TP. The inclusion of reports of randomised trials published in languages other than English in systematic reviews. Health Technol Assess 2003; 7(41): 1-90 [https://doi.org/10.3310/ hta7410][PMID: 14670218].

84. Häusser JA, Mojzisch A, Niesel M, Schulz-Hardt S. Ten years on: a review of recent research on the job demand-control (-support) model and psychological well-being. Work Stress. 2010;24(1):1-35. https://doi.org/10. 1080/02678371003683747.

85. van der Doef M, Maes S. The job demand-control (-support) model and psychological well-being: a review of 20 years of empirical research. Work Stress. 1999;13(2):87-114. https://doi.org/10.1080/026783799296084.

86. Mazzola JJ, Disselhorst R. Should we be "challenging" employees? A critical review and meta-analysis of the challenge-hindrance model of stress. J Organ Behav. 2019;40(8):949-61. https://doi.org/10.1002/job.2412.

87. Jewitt C. Multimodal methods for researching digital technologies. In: Price S, Jewitt C, Brown B, editors. The SAGE handbook of digital technology research. London: SAGE Publications; 2013. p. 250-65.

88. Slavish DC, Graham-Engeland JE, Smyth JM, Engeland CG. Salivary markers of inflammation in response to acute stress. Brain Behav Immun 2015; 44: 253-69 [https://doi.org/10.1016/j.bbi.2014.08.008.][PMID: 25205395].

\section{Publisher's Note}

Springer Nature remains neutral with regard to jurisdictional claims in published maps and institutional affiliations.

\section{Ready to submit your research? Choose BMC and benefit from}

- fast, convenient online submission

- thorough peer review by experienced researchers in your field

- rapid publication on acceptance

- support for research data, including large and complex data types

- gold Open Access which fosters wider collaboration and increased citations

- maximum visibility for your research: over $100 \mathrm{M}$ website views per year

At BMC, research is always in progress.

Learn more biomedcentral.com/submissions 